\title{
CULTURA DE CALIDAD EN LA FORMACIÓN DE RECURSOS HUMANOS EN LAS UNIVERSIDADES: VENTAJA COMPETITIVA PARA LA INSERCIÓN EN EL MERCADO LABORAL
}

\author{
Ing. Manuel García Pantigozo* \\ E-mail: calidadtotal@hotmail.com \\ Ing. Luis Ráez Guevara** \\ E-mail: kaizsen_group@hotmail.com
}

\author{
RESUMEN
}

Las instituciones que forman recursos humanos, deben velar por estar al tanto de las tendencias del mercado con respecto a los conocimientos y competencias laborales que se requieren. En este trabajo, lo que se intenta es demostrar con datos extraídos del mercado de demanda laboral la importancia de la implementación de los diferentes sistemas de gestión en los cursos de formación.

\section{ABSTRAST}

The institutions that form human resources, should look to be the so much of the tendencies of the market with regard to the knowledge and labor competitions that are required. In this work, what is attempted is to demonstrate with extracted data of the market of labor demand the importance of the implementation of the different administration systems in the formation courses.

PALABRAS CLAVES: calidad, servicio, universidad, mejoramiento, métodos, académico.

KEY WORDS: quality, service, university, improvement, methods, academic.

\section{EL PROBLEMA}

La globalización a convertido al planeta en una aldea global, cada día surgen nuevos paradigmas y estos a su vez son reemplazados por otros recientes $y$ de esto no escapa la Universidad que forma profesionales en diferentes campos. Por efectos de la globalización y la competitividad, las empresas tienen que bregar diariamente para no perder el paso, y para esto dependen de la calidad de sus recursos humanos y su mayor proveedor de este recurso sigue siendo la Universidad, es alli donde se forman los que dirigirán tecnologicamente las empresas y con esto se estaría dejando de lado al empírismo que si bien puede ser exitoso en un determinado momento, también tiene muchas limitaciones. La tendencia actual de la empresas es de acreditarse mediante Normas ISO 9000 (Gestión y Aseguramiento de la Calidad) e ISO 14000 (Gestión del Medio Ambiente). que si bien en un momento dado servian como una carta de presentación para un mercado externo exigente, ahora se ha vuelto una necesidad para competir internamente. Se necesita que los empleados y en ospecial los profesionales quienes van a liderar el cambio, tengan una base con respecto a la cultura de calidad y para ser mas puntual con la cultura de normalización, por todo esto, la Universidad debe cambiar en función de los ruidos del mercado

Con este trabajo se quiere demostrar la importancia que significa hacer los cambios necesarios respecto a la formación de recursos humanos y la introducción de una "cultura de calidad" en las diversas profesiones.

\section{Problema General}

¿Será una ventaja competitiva la inclusión de una cultura de calidad en los cursos de tormación profesianal que brinda la Universidad?

\section{Objetivos}

a) Determinar ¿Cuál debe ser el cambio a desarrollarse en los cursos que se desarrollan en la formación de profesionales?

b) ¿Qué otras habiłidades y competencias deben acompañar a este recurso humano para satisfacer la demanda empresarial?

\section{Hipótesis}

La inclusión de una cultura de calidad en los cursos de formación de próesionales, permitirá como ventaja competitiva aumentar las posibilidades de que éstos se inserten en el mercado laboral dentro de los esquemas actuales de globalización y competitividad.

\section{Variables e Indicadores}

Variables dependiente

Formación académica-profesional. 


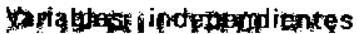

\section{Cutrura de calíkad}

\section{MARCO TEORICO}

\section{ANTECEDENTES DEL PROBLEMA}

\section{ENTORNO GENERAL}

El mercado de los recursos humanos que se forman en las diferente instituciones de educación superior está claramente definido, y esta compuesto por la empresa privada y estatal. Con respecto a la emprasa privada, esta tiene que hacer frenteja un conjunto de fuerzas corrpetitivas recursos humanos Las empresas de nuestro medio están amenazadas por Ja competencia global, en algunos casos sus ejecutivos no tienen bien claro la estructura del sector industrial en el cual se encuentran y que os lo que deberían hacer frente a la competencia Actualmente las empresas conocidas como orgarizaciones de Respuesta Sensible Rápida (ORSS) consideran como vital la calidad de sus rocursos humanos, estas empresas capacitan a sus empleados dentro de un esquema de innovación y adquisición de nuevos conocimientas, lós cua les se revierten en la empresa, este tipo de empresas pertenecen mayormente a capitales transnacionäles o son empresas nacionales líderes en un sector industrial del país. $Y$ las preguntas: ¿Qué será de las empresas que no pertenecen a capitales transnacionales o que no son líderés en el 'mercado ? "Podrán "mattenerse en el mercado?, ¿Podrán tener la oportunidad y lớs recursos suficientes de reciclar a su personal?. $O$ es que se hace necesario, que los recursos humanos quire salen de los institutos de educación superior tengan un nivel de competencia a la cual se adícíonatía cierto tipo de conocimiertos y experiencias tNo deberian estas instituciones formadoras de recursós humanos tenter un sistema de retroalimentación de información, el cual les permita conocer el mercado laboral, para hácer'cáribios necesarios en sus planes curriculares, (de acuerdo a muevast recesidades y tendenclas, a tos huvevos requerimientos' del merécado?; tNo son ellos er parte responsables de que sus egresados ho fiayan desarrollado en fricictios de los cases certipetencias de

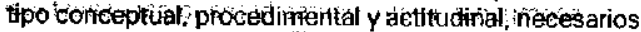
para insertarse en le mercado-faboral? ino es cierto. que las empresas competitivas no solo se caracterizan por su liderazgo en el mercado, sino que elitecuiso quie hace valioso a los demás recursos (financieros y tecnológicós) es el recúrso humano?

ENTORNO ACTUAL DE LA INDUSTRIA

En el Pérữ cambios por efectus de la glabalización y por el esquerna económico del libre mercado (privatización. disminución de impuestos; etc), bajo e criterio de costa/ beneficio. muchas empresas se colvirtieron en importadoras, otras cerraron, otras sobreviven haciendo frente a productos mas competitivos (calidad y menores precios) y las quo lodawa benlan ventajas competitivas. tuvieron que hacer inversión en nuevas tecnologias.

\section{BASES TEORICAS}

\section{CARRERA DE INGENIERIA QUIMICA (un modelo de investigación)}

Es la profesión en la cual el conocimiento de las matemáticas, química $\gamma$ ptras ciencias naturales, obtenido mediante el estudio, la experiencia y la práctica es aplicado con razonamiento juicioso para desarrollar formás económicas de uso de materiales y energia a nivel industrial para el beneficio de la humanidad. Es una protesión con fundamentos científicos filośóficos. doctrinanos y tecnológicós y se desamolla en quince universidades nacionales.

\section{GESTIÓN DE OPERACIONES}

Los aleances que trene la Gestion de Operaciones; hoy son entendidos de modo diferente y no como eran años attás. El problema de próducción abarca desde la generación de phaterias primas e insumos hasta la entrega final del producto o servicio al Cliènte En esta amplia linea se generan gran cantidad de problemas que son abordados de diversas maneras. siendo de particular utilidad unia contecta definicion de los esquemas de gestión, el modelamiento matemático $y$ las tecnologías de información Estos elementos son claves para enfrentar la compleja realidad en que se desenvueiven tas : empresas actualmente. Mundialmente, las operactones, ent una empresa moderna se han conventide en un arma competitiva fundarmental.

\section{GESTIÓN AMBIENTAL $180-14000$}

ISO 14000 encárna tin nievo enfoque a la proteccion del medio ambiente. En desafio a cada organización a hacelr acopio de sus aspectos rambientales; a establecer sus propias metas y otjpetivos, a comprometerse paracadoptar procesos efectives:y confiables; und mejora constante, hacer que colaboradores y gerentes practiquen in sistema de përcepción e llustracióntcompartido y responsabitidad personal por el desempeño ambiental de la organzación. Este nutevo paradigha promete establecer una base súlida con una administración consistente y consciente de las obligaciones con el medio ambiente.

Accidentes industriales recientes, algumos de los cuales provocaron considerables daños al ser humano y al medio ambiente; han demestrando que el cumplamiento de reglamentos no es suficiente para garantizar que no se produdirá una degradación del entorno. Para la protección del medio ambiente, surgió la percepción de la necesidad de un sistema más proactivo La base de todala serielSO 14000 estrategia de protección ambiental proactiva: en la que el cumplimiento de reglamentos no es más que uno de 
los elementos de un enfoque más inclusivo y de cobertura global. ISO 14001 la norma del sistema de administración ambiental, presenta un marco para dirigir aso de los recursos organizacionales a la cobertura completa de los impactos actuales y potenciales a través te procesos administrativos confiables y una base de polaboradores educados, asimismo comprometidos.

\section{GESTIÓN Y ASEGURAMIENTO DE LA CALIDAD ISO 9000}

En el Perú se esta trabajando con la Serie de Wormas ISO 9000 desde 1987, estas normas sirven como gula para la implementación de la Gestión y Aseguramiento de la Calidad en la empresa, establece tas exigencias mínimas que una empresa debe cumplir dentro de sus operaciones para asegurar la calidad de sus productos. Estas normas se clasifican en: Normas contractuales o de aseguramiento de la calidad: ISO 9001 Modelo para el aseguramiento de la calidad en el diseño. desarrollo, producción, instalación y servicio post venta; iso 9002- Modelo para el aseguramiento de la calidad en producción, instalación y servicio post venta;y ISO9003 - Modelo para el aseguramiento de la calidad en la inspección y en los ensayos finales (esta norma regula solo el Control de Calidad).

Normas no contractuales o de gestión de la calidad: creadas para ayudar a las empresas a establecer el Sistema de la Calidad mediante Normas para la gestión de la calidad y el aseguramiento de la calidad tenemos a: ISO 9000-1, ISO 9000-2, ISO 9001, ISO 9002 e ISO 9003, ISO 9000-3, ISO 9000-4, ISO 9004-1, Guía ISO 9004-2, ISO 9004-3, ISO 9004-4, ISO 9004-5, ISO 90046 y ISO 9004-7. Actualmente estas normas están en plena revisión por un Comité Técnico en INDECOPI.

\section{CONTROL AMBIENTAL}

Las empresas necesitan profesionales que conozcan sobre legislación ambiental, química ambiental, microbiología ambiental, diseño de experimentos. procesos de tratamientos de aguas residuales, procesos de tratamientos de descargas a la atmósfera, procesos de manejo, disposición y confinamiento de residuos peligrosos, evaluación del impacto ambiental, estudios de riesgo ambiental y auditorías ambientales.

\section{GESTIÓN DE CALIDAD}

El contenido de "Gestión de calidad", muestra lạinserción interactiva del sistema calidad en el sistema total de la empresa industrial y su entorno comunitario e intemacional con que se intercambia, partiendo de la definición inicial de necesidad de un servicio hasta su satisfacción plena por un producto, puntualizando en todas las etapas técnicas, económicas y legales propias $y$ de proveedores, la responsabilidad $y$ trascendencia de todos los sistemas conformantes de la industria $y$ aún del pais, para que el producto se conciba. produzca y use con la mayor factible calidad.

\section{MONITOREO AMBIENTAL}

Las industrias pesquera, minera, textil, generan contaminación ambiental, para contrarrestarlas. la industria requiere personas capacitadas en el campo del monitoreo ambiental. Actualmente en el país, recién se están fijando y definiendo los estándares de calidad (aire, agua y suelo), en este trabajo participan equipos multidisciplinarios, donde el ingeniero químico tiene un rol que cumplir, conoce sobre procesos de transformación y sus respectivos agentes que se difunden en el ambiente.

\section{SEGURIDAD E HIGIENE OCUPACIONAL - ISO 18000}

La seguridad y la higiene en el trabajo, son aspectos que logran el desarrollo estratégico de las empresas. También debe involucrarse la atención sobre los riesgos que la actividad genera sobre la salud de las personas que llevan adelante el proceso de producción. Para ello, existe una norma específicamente abocada a la gestión de programas de salud y seguridad ocupacional; se trata de la norma ISO 18000. Se analiza permanentemente el riesgo que puede ocasionar cada tarea sobre la persona que la realiza, y en función de ello se establecen programas de prevención de accidentes y las actividades correctivas que se requieran. Específicamente se incluyen actividades de medición y control en los puestos de trabajo, como audiometria, ergonometría, etc. La implementación de un programa de seguridad y salud ocupacional, requiere como punto de partida la realización de una evaluación inicial de la situación de la planta en materia de seguridad laboral y un diagnóstico acerca del marco legal vigente.

\section{CONTROL DE CALIDAD}

Las empresas necesitan producir productos con características homogéneas prefijadas, y para comprobar esto, necesitan llevar a cabo controles de calidad. y esto lo pueden realizar en laboratorios o con equipos sofisticados. En una empresa el departamento de Control de Calidad verifica que se cumplan los rangos de la especificación para los diferentes productos que procesa. El no hacerlo, puede significar que la empresa pierda competitividad y salga del mercado.

\section{ANÁLISIS Y RIESGOS EN PUNTOS CRÍTICOS DE CONTROL - HACCP}

En los últimos años, se ha prestado quizás demasiada atención al análisis microbiológico de los productos finales de los alimentos y no a modernizar las industrias y corregir los defectos que suelen ser causa de alteraciones microbianas e incluso de enfermedades en el consumidor. Por otra parte. los requisitos de los reglamentación técnico-sanitarias, son muy numerosas, lo que hace imposible el cumplimiento de todas ellas. y lo más importante dificulta el establecimiento de prioridades. La filosofía del sistema HACCP no es nueva, puesto que el énfasis 
que pone en la prevención de riesgos ha sido desde sus origenes el objetivo primordial de la higiene de los alimentos.

\section{METODOLOGíA}

\section{TIPO DE INVESTIGACIÓN}

La investigación es descriptiva Por el tipo de investigación, no se trabajará cuantitativamente con variables, pero si con necesidades tangibles.

\section{POBLACIÓN Y MUESTRA}

El universo esta conformado por toda la demanda de bachilleres o titulados en ingeniería Química existente en todo el pais, esta demanda puede ser satisfecha por mediante:

Avisos en los diarios (de circulación nacional y local). Cazadores de talentos.

Contacto con universidades (personal, correo, fax, e-mail).

- Bolsas de trabajo tradicionales fOYR. CAMPOVERDE, BDO, etc.)

Bolsas de trabajo electrónicas (wnw.laborum.com) - Otros.

Se ha considerado como muestra a la demanda laboral existente en el periodo comprendido del 1 de enero 1999 al 19 de marzo del 2000, y que ha sido publicada en el diario El Comercio.

El total de demanda durante ese periodo es de 132 (bachilleres o titulados en Ingeniería Química).

\section{ANALISIS DE DATOS}

\section{RESULTADO DEL ANALISIS DE LA MUESTRA}

- El $25,76 \%$ del total de la demanda de egresados de Ingenieria Química son para cargos de responsabilidad, $y$ que al desagregarlo se tiene que:

- El $6,06 \%$ tenga competencias son para Jefe de Planta;

- El $6.06 \%$ tenga competencias son para Jefe de Laboratorio;

- El $3,79 \%$ son tenga competencias para Jefe de Producción;

- Yel3,03\% tenga competencias son para Supervisor de Producción;

- Respecto a la demanda por experiencia se tiene que:

- El $93,18 \%$ es para personas con experiencia entre 1 Y 4 años;

- $Y$ el $6,82 \%$ para personas con experiencia mavor de 4 años;

- Respecto a la edad la demanda es como sigue:

- De 25 a 30 años la demanda es de 4,55\%;

- De 31 a 35 años la demanda es de $3.03 \%$;

- De mayores de 35 años, la demanda es de años $3.79 \%$ :

- el $88,63 \%$ de la demanda no especifica la edad;

- El $41.17 \%$ requiere que tenga competencias en Gestión de Operaciones:

- Que el $18,18 \%$ tenga competencias en Gestión Ambiental y Normas ISO 14000 ;

- Que el $17.42 \%$ tenga competencias en Aseguramiento y Gestión de la Calidad ISO 9000;

- Que el 15.15\% tenga competencias en Control Ambiental:

- Que el $14,39 \%$ tenga competencias en Gestión Total de la Calidad (TOM):

- Que el $13.64 \%$ tenga competencias en Monitoreo Ambiental:

- Que el $7.18 \%$ tenga competencias en Seguridad é Higiene Ocupacional (ISO 18000):

- Que el $5.30 \%$ tenga competencias en Control de Calidad:

- Que el $4,55 \%$ tenga competencias sabre la Norma de Calidad en Alimentos HACCP

\section{CONCLUSIONES}

Se puede concluir en forma general:

- El fenómeno de la globalización está estandarizando la demanda de recursos humanos a nivel global, la necesidad de las empresas con capitales foráneos o de una empresa que exporta, trae consigo que también se estandarice los recursos humano, que en realidad es quien maneja los procesos y productos.

- Las empresas en el pais conocen qué tipo de profesional necesitan y para esto hacen un benchmarking con sus homólogos de afuera o con los líderes en el mercado, y es par eso que son puntuales al hacer su requerimiento.

- Las facultades donde se imparte la carrera de Ingenieria Química, que en el caso del Perú todas pertenecen a Universidades Publicas, deben tener en cuenta al mercado de recursos humanos.

- La tendencia es que los sistemas de gestión se vayan integrando. y esto significa que las empresas buscaran recursos humanos que tengan competencias en el Sistema Integrado de Gestión que viene hacer la integración de Sistema de Gestión y Aseguramiento de la Calidad ISO 9000 mas el Sistema de Gestión Ambiental ISO 14000 y el Sistema de Gestión de Seguridad a Higiene Ocupacional ISO 18000, a la cual próximamente se añadiría el Sistema de Gestión de Recursos Humanos ISO 24000. 


\section{GRÁFCO N'OI REQUERIMIENTO}

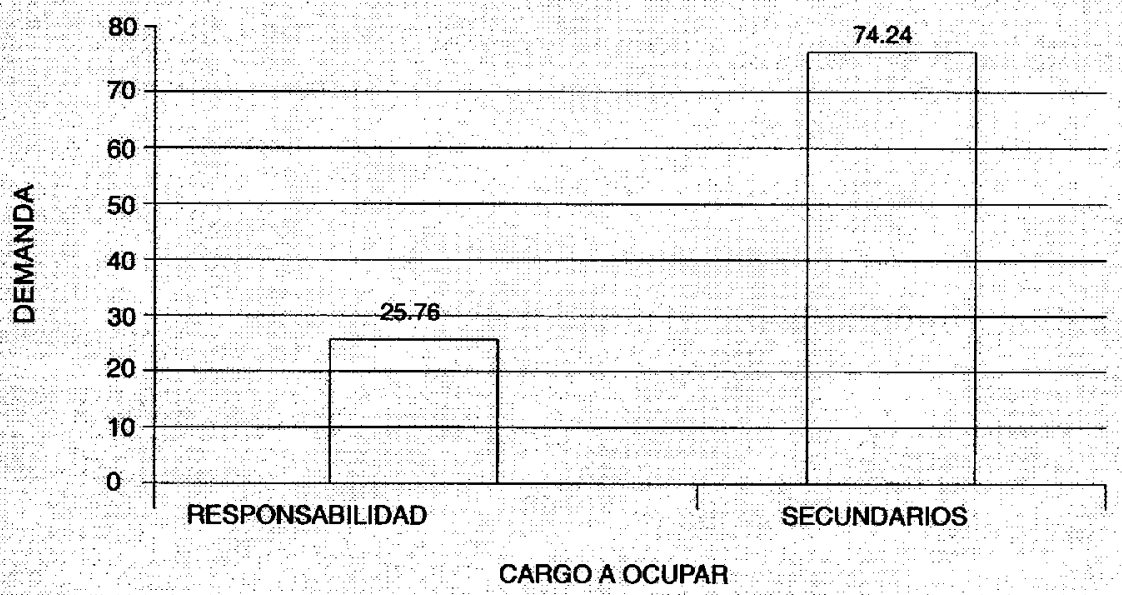

GRÁFICO N’02 CARGOS

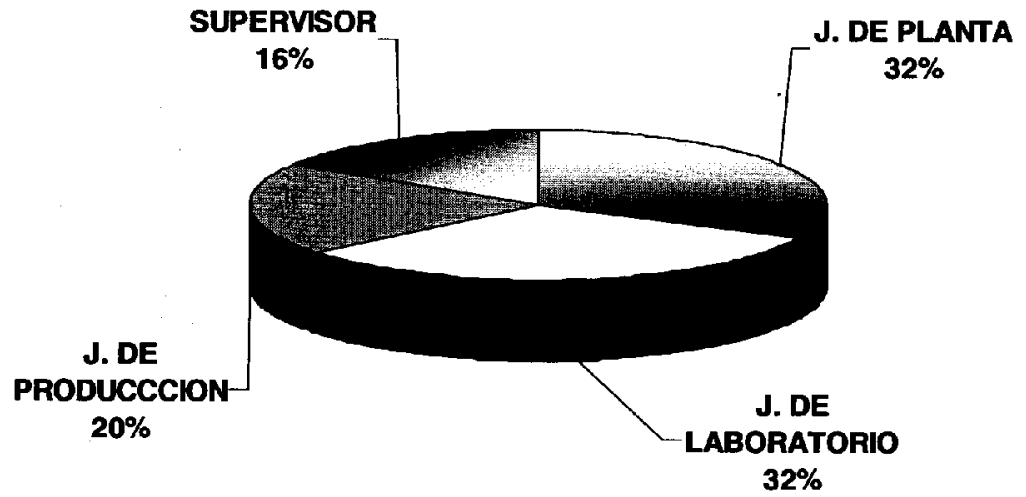




\section{GRÁFICO N ${ }^{\circ} 03$ EXPERIENCIA LABORAL}

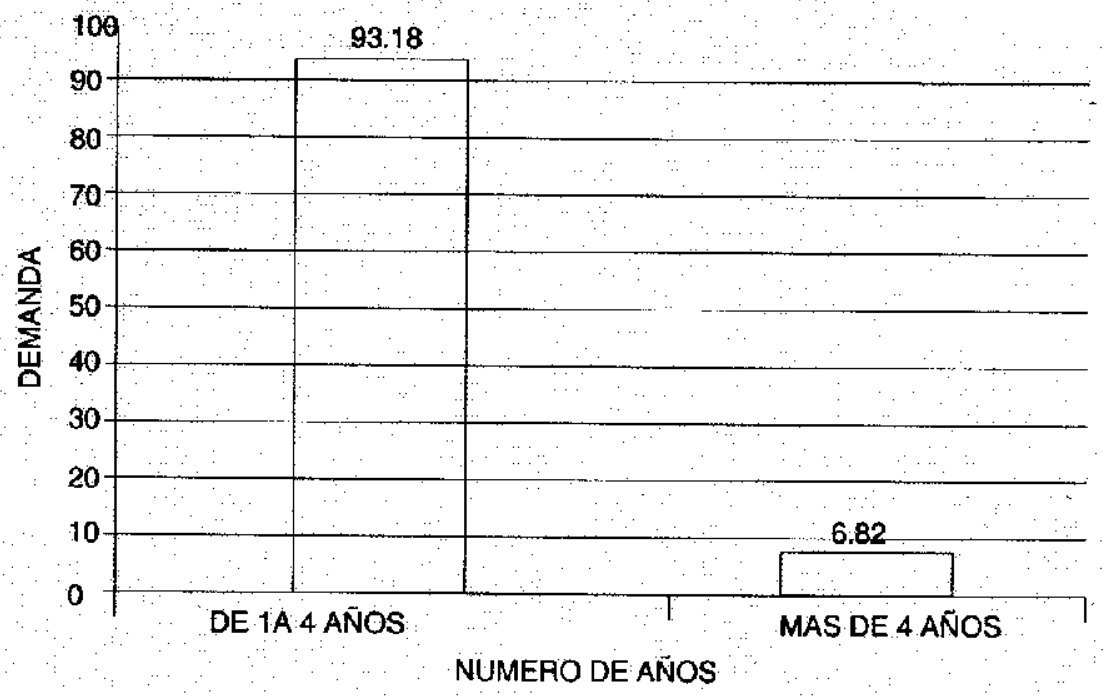

GRAFICO N 04: POR EDADES

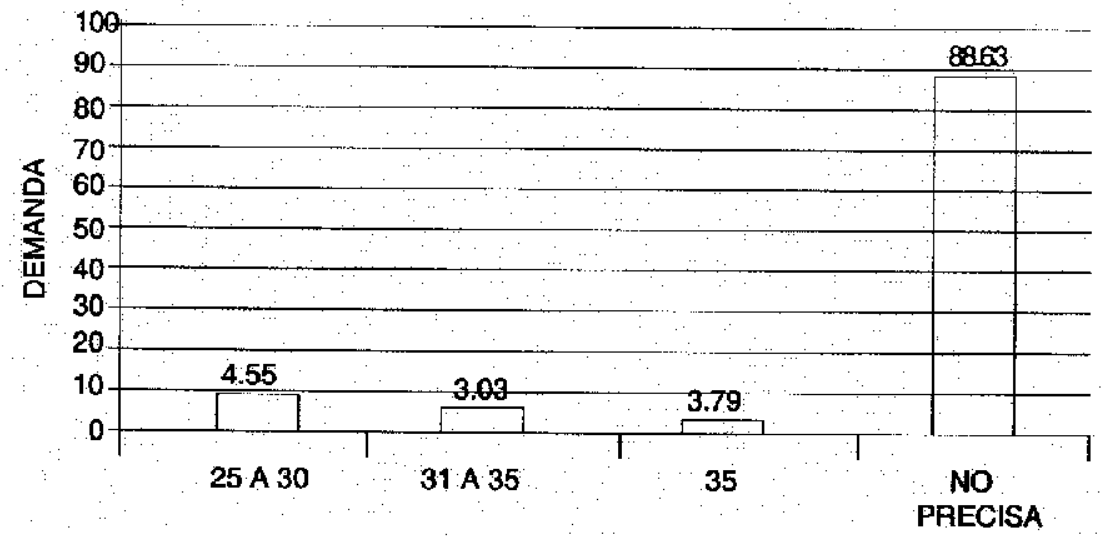

CATEGORIAS 


\section{GARGON os CONGCMIENTO DE LIOUAS}

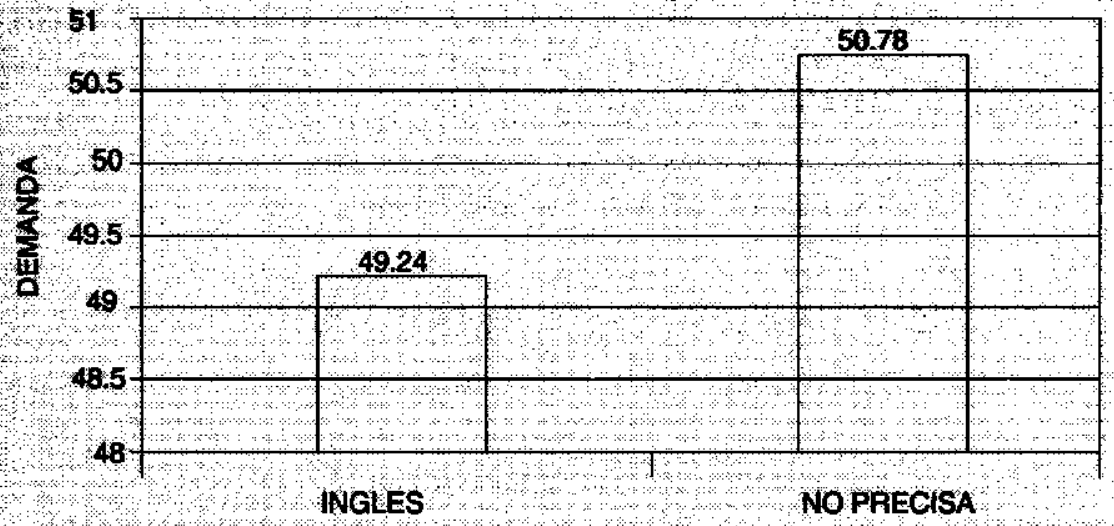

REQUERIMIENTO

GAAFICON 06. CONOGIMIENTOS EN GESTION DE OPERACIONES

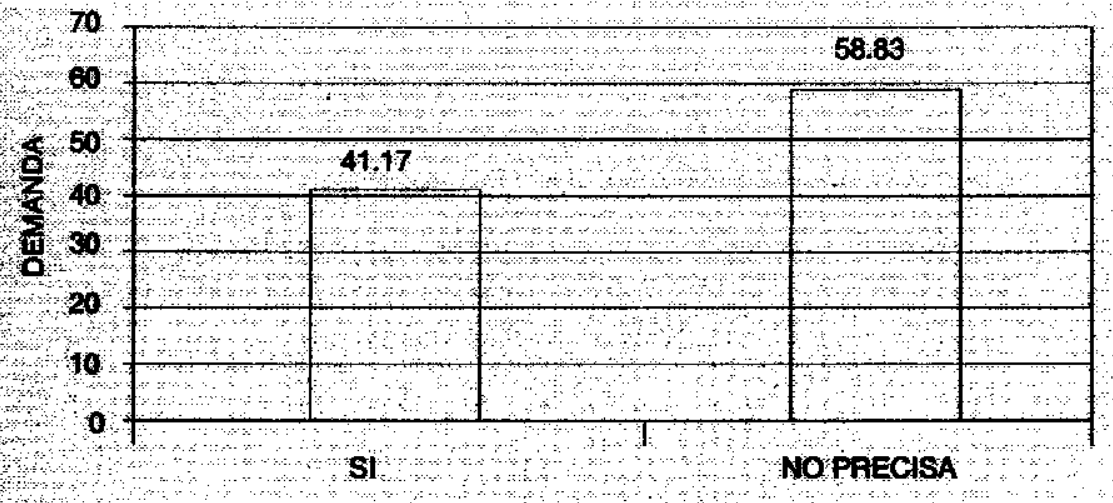

REQUERIMIEMTO 


\section{GRAFICO N 07 CONOCIMIENTOS SOBRE GESTIÓN AMBIENTAL $Y$ NORMAS ISO 14000}

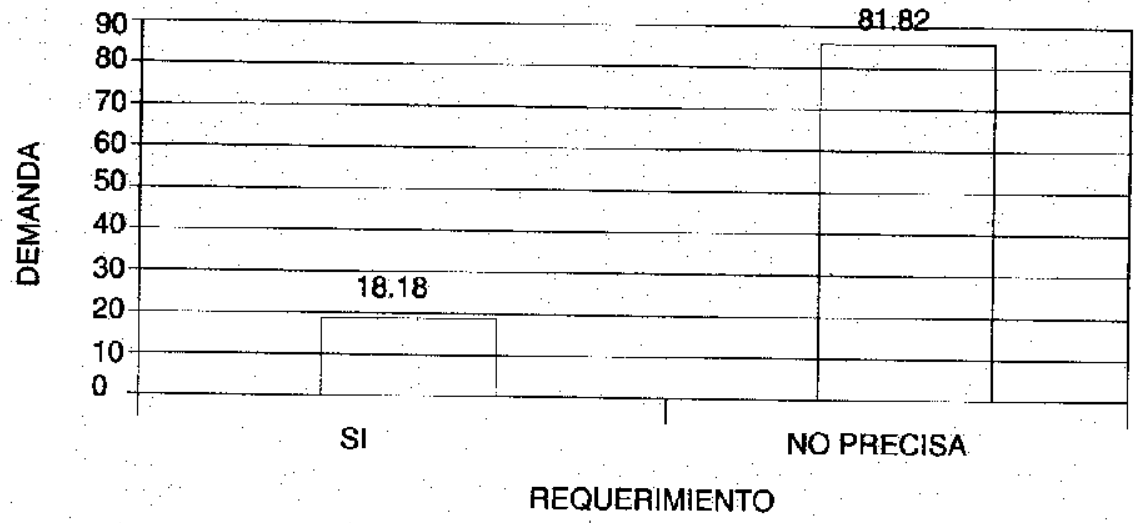

GRÁFICO N०08: CONOCIMIENTOS SOBRE NORMAS ISO 9000

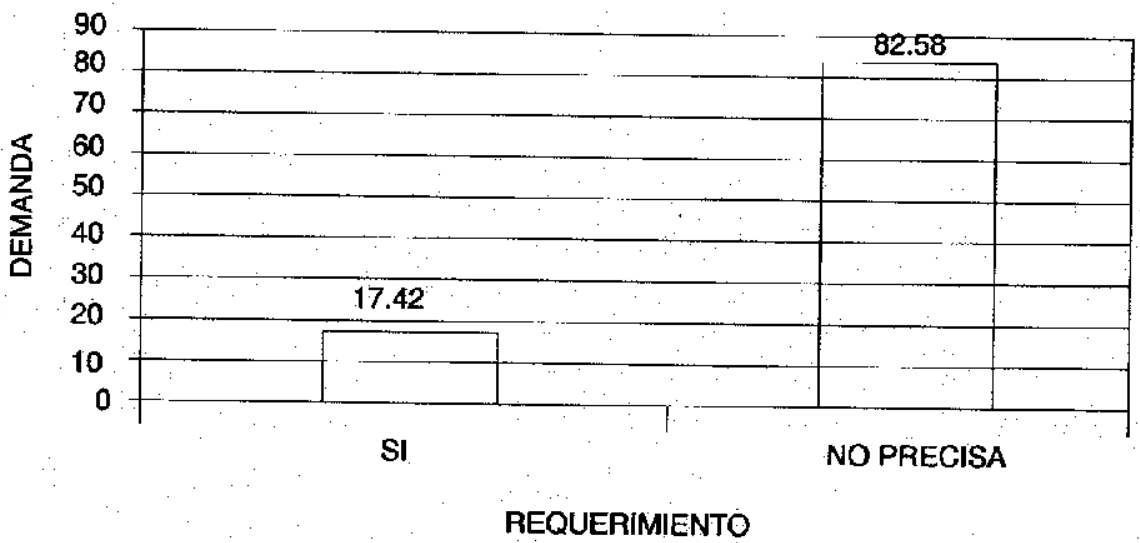


GRÁFICO N 09 : CONOCIMIENTOS SOBRE

SEGURIDAD E HIGIENE OCUPACIONAL

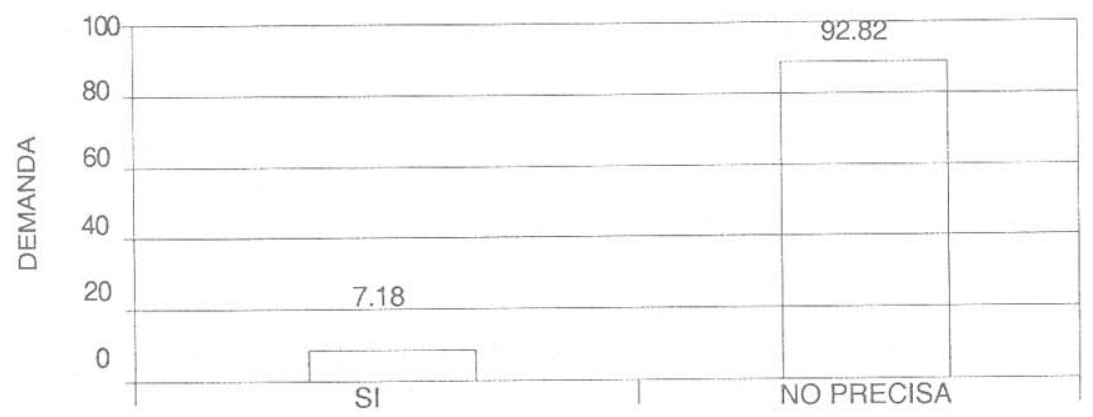

REQUERIMIENTO

GRÁFICO N 10: CONOCIMIENTOS SOBRE

HACCP

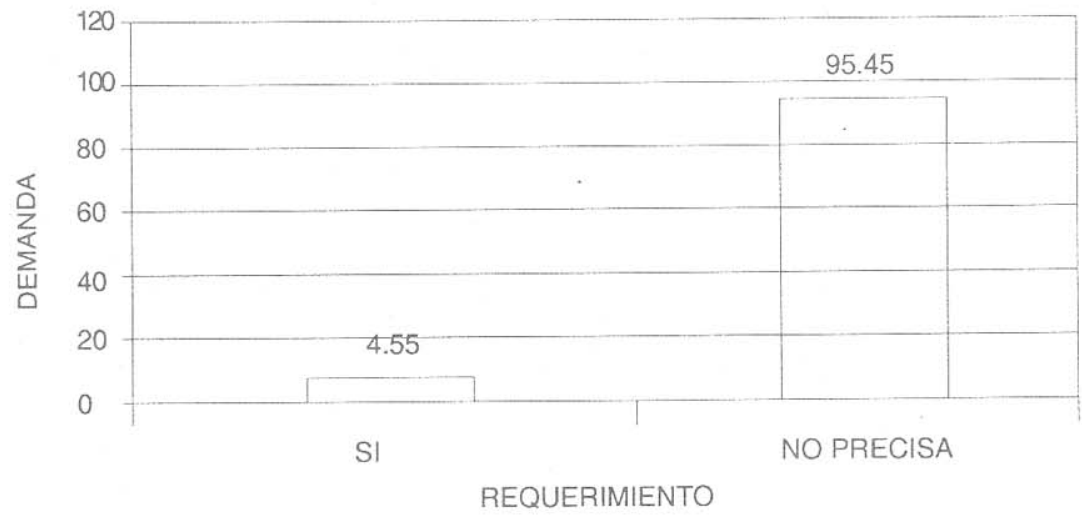




\section{BIBLIOGRAFIA}

MANUEL GARCIA-PANTIGOZO

"Cultura de la Calidad" UNMSM 1994.

MANUEL GARCÍA-PANTIGOZO,

"Cultura de la Normalización" Revista INDUSTRIAL DATA Vol. 1. N 2 Diciembre 1998 Fll - UNMSM.

MANUEL GARCÍA-PANTIGOZO Y LUIS RAEZ GUEVARA "Los Premios Nacionales a la Calidad - I Parte" Revista INDUSTRIAL DATA Vol. 1. $\mathrm{N}^{\circ} 2$ Diciembre $1998 \mathrm{Fll}$ - UNMSM.
MANUEL GARCIAA-PANTIGOZO y LUIS RAEZ GUEVARA "Modelo de Implementación de Métodos Modernos para Mejorar la Calidad de los Servicios Académicos Administrativos en la Facultad de Ingeniería Industrial", Revista INDUSTRIAL DATA Vol. 2, No 1 Julio 1999 FII . UNMSM.

MANUEL GARCÍA-PANTIGOZO $Y$ LUIS RAEZ GUEVARA "Los Sistemas Integrados de Gestión". Revista INDUSTRIAL DATA Vol. 2, N² Diciembre 1999 FII - UNMSM.

DIARIO EL COMERCIO, Enero 1999 a Marzo 2000
(*) Ingeniero Químico - UNMSM. Estudios de Maestría en Ing. Industrial $y$ en Administración. Profesor Asociado on la Facultad de Química e Ingeniería Química de la UNMSM en la cátedra de Administración de la Producción y de la Calidad. Docente en la Facultad de Relaciones Industriales - USMP en la cátedra de Gestión de Operaciones. Investigador de la Unidad de Investigación de la FOIO - UNMSM. Miembro del Comité Técnico de Gestión y Aseguramiento de la Calidad ISO 9000 - INDECOPI. Miembro del Comité de Gestión de la Calidad - S.N.I.

(**) Ingeniero Industrial - UNMSM. Estudios de Maestria en Ing. Industrial - UNMSM. Profesor Asociado Facultad de Ingeniería Industrial UNMSM. Evaluador del Premio de la Calidad 1998. Gerente de Producción de la Panadería de la FII - UNMSM. 